\title{
MRI Aspects of Prenatal Brain Malformations about Three Cases and Literature Review
}

\author{
Touré Aboulaye $^{1 *}$, Ahoury Judicael ${ }^{2}$, Ndja Ange $\mathrm{P}^{1}$, Ledion Anicet ${ }^{1}$, Gbazi Casimir ${ }^{1}$ \\ ${ }^{1}$ Department of Radiology, University Hospital in Cocody, Abidjan, Côte d'Ivoire \\ ${ }^{2}$ Department of Radiology, Cardiology Institute in Abidjan, Côte d'Ivoire
}

\begin{abstract}
Article History
Received: 14.09 .2021

Accepted: 20.10 .2021

Published: 08.01.2022

Journal homepage:

https://www.easpublisher.com

Abstract: We report three cases of fetal malformations diagnosed by MRI in Abidjan. Patients were referred for suspicion of fetal malformations on ultrasound. They were young (average age of 29 years), primipares, without any particular antecedent. We used a $1.5 \mathrm{~T}$ MRI, T2 coronal, T2 axial, BTFE coronal, BTFE sagittal, BTFE axial, diffusion and ADC cartography were realised. MRI diagnosed an arachnoid cyst, posterior fossa kystique tumor, hydranencephaly. MRI is an excellent diagnostic tool for fetal malformations. Its use should be routine in management of fetal malformations.
\end{abstract}

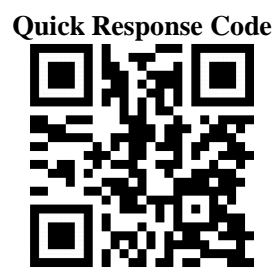

Keywords: MRI, Antenatal Brain Malformation, Abidjan.

Copyright (C) 2022 The Author(s): This is an open-access article distributed under the terms of the Creative Commons Attribution 4.0 International License (CC BY-NC 4.0) which permits unrestricted use, distribution, and reproduction in any medium for non-commercial use provided the original author and source are credited.

\section{INTRODUCTION}

Antenatal diagnosis of fetal malformations is mainly based on ultrasound examination [1]. However, it is not always able to identify all foetal abnormalities, particularly neurological pathology [2]. Fetal MRI is an important diagnostic complement [3]. Unlike ultrasound, fetal MRI is not limited in cases of oligoamnios, obesity or engagement of the fetal head in the pelvis at the end of pregnancy [3, 4]. In addition, it appears unavoidable in the examination of the posterior cerebral fossa because the ultrasound study is extremely limited due to the artifacts of the bone structures $[3,5]$. Several studies have shown that fetal MRI has changed parental counseling and management of pregnancy [3]. In sub-Saharan Africa, the practice of fetal MRI is quite recent in the diagnosis of fetal malformations. This study reports 3 cases of prenatal cerebral malformations on MRI with emphasis on it's diagnostic interest.

\section{ObSEVATIONS}

Case 1: Primigravida and primiparous of 36 years old is referred by a gynecologist for fetal MRI. Her biological test was normal. She performed an ultrasound at 34 weeks of amenorrhea which showed a dilatation of 3rd and 4th ventricles with a suspicion of Dandy Walker type malformation. The rest of the fetal morphology was normal on ultrasound. We used $1.5 \mathrm{~T}$ MRI. The following sequences were carried out; T2 coronal, T2 axial, BTFE coronal, BTFE sagittal, BTFE axial and diffusion with ADC mapping. Fetal MRI revealed a cystic formation behind the 3rd ventricle in hyposignal $\mathrm{T} 1$, hypersignal $\mathrm{T} 2$ and diffusion with high ADC evoking an arachnoid cyst. MRI did not detect any other associated abnormalities (figure1).

Case 2: A 33-year-old patient primiparous, 2nd pregnancy is referred for fetal MRI. She had not performed any biological tests. She performed an ultrasound at 32 weeks amenorrhea. This ultrasound revealed a cystic formation in the posterior fossa containing hyperechoic vegetation. There was no supratentoral abnormalities (no dilatation of ventricles). The rest of the fetal morphology was normal on ultrasound. The diagnosis of Dandy Walker type malformation has been evoked (fig 2 a). Fetal MRI confirmed a cystic mass in the posterior brain fossa. the mass was wellcontoured, dual-component, with the cystic portion in hypersignal $\mathrm{T} 2$ and the tissue portion in hyposignal $\mathrm{T} 2$ in favor of a cystic tumor process (fig2 b,c).

Case 3: Primigravida and primiparous of 20 years old is referred for fetal MRI. Her biological test was normal. Obstetrical ultrasound at 20 weeks 
amenorrhea showed hydrocephalus. Ultrasound at 31 SA showed hydrocephalus with non-existent cerebral parenchyma (fig 3a). MRI was carried out in order to assess the lesions observed on ultrasound. MRI revealed absence of supratentorial cerebral parenchyma occupied by a fluid cavity in hypersignal $\mathrm{T} 2$, posterior fossa was normal (fig3 b). Hydranencephaly was evoked.

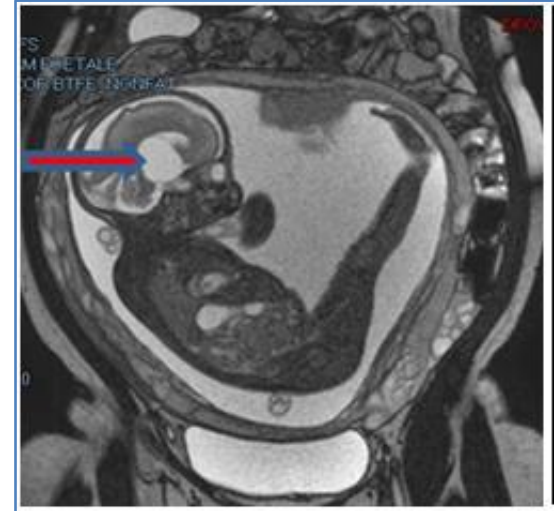

a

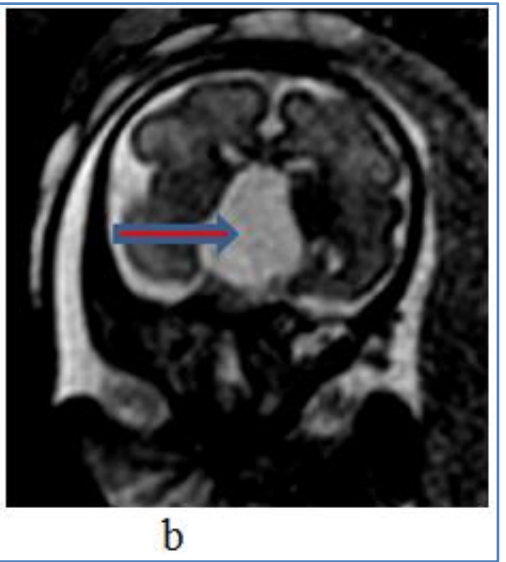

Fig-1: MRI T2 sagittal(a) and coronal(b), cystic formation behind the 3rd Ventricle in T2 hypersignal and diffusion: Arachnoid cyst

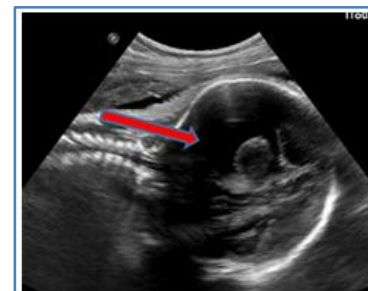

a

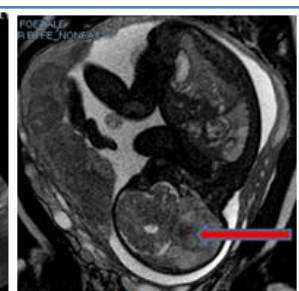

b

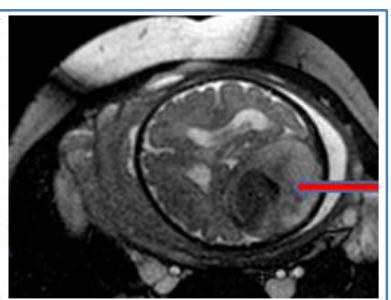

c

Fig-2: a Ultrasound, cystic formation of posterior fossa with intracystic vegetation. b,c MRI, T2 axial and sagittal; dual component mass cystic in hypersignal and tissue portion in hyposignal

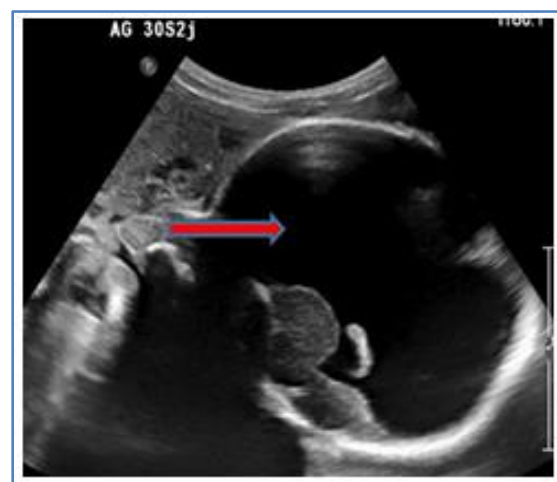

a

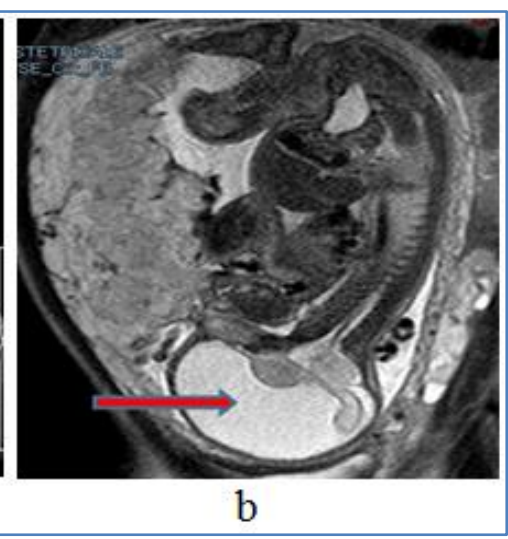

b

Fig-3: A, fetal ultrasound at 31 Weeks: suspicion of hydrocephaly. b MRI sagittal T2; absence of supra-tentorial cerebral parenchyma occupied by T2 hypersignal fluid cavity and integrity of posterior fossa: Hydranencephaly

\section{DiSCUSSION}

Bright first described arachnoid cyst as a formation whose walls are purely arachnoid. This cyst contains cerebrospinal fluid of the same composition as the circulating cerebrospinal fluid and communicates with the adjoining arachnoid lakes allowing a regular exchange of intracystic fluid[6]. In MRI, it is a posterior fossa cyst (hyposignal T1 and frank hypersignal T2), central, non-communicating and normal morphology of 4th ventricle and cerebellum. Arachnoid cyst of the posterior fossa appears to have a favourable prognosis[6]. Malformations of posterior cerebral fossa are frequent indication for MRI, the prognosis being strongly related to the anatomical structures of posterior fossa, such as absence of curvature of pons, partial or total agenesis of vermis which are criteria of poor prognosis [7]. "Posterior fossa cyst" is evoked when the anteroposterior diameter of large cistern exceeds $10 \mathrm{~mm}$ on ultrasound. A cystic aspect of posterior cerebral fossa may correspond to anomalies of very varied nature and prognosis: Dandy-Walker malformation, 
cerebellar dysplasia, mega-cistern, arachnoid cyst. The cystic aspect is discovered on axial cerebral sections, but it is the strict sagittal section that will allow a correct study of the malformation [8]. MRI is therefore a very good indication in case of suspicion of posterior fossa anomalies to analyze the brain stem and cerebellar vermis. A mega cistern or arachnoid cyst can be evoked when brain stem and vermis have normal morphology. These pathologies have a better prognosis[9]. Malformations of the posterior fossa are mainly cerebellar, prenatal diagnosis is not always easy because of late growth of the cerebellum: hypoplasia can often only be diagnosed after the thirtieth week [10]. In addition, it is sometimes difficult with both ultrasound and fetal MRI to recognize a vermian abnormality if there is no cystic dilatation of the 4th ventricle. The classification of these cerebellar abnormalities is the subject of both clinical and genetic research, but many unknowns remain. Hydranencephaly is characterized by the absence of cerebral hemispheres, which are replaced by a cyst bordered by a thin membrane limited on its outer surface by the leptomeninge [11].

Our diagnosis of hydranencephaly was evoked during an obstetrical ultrasound at 31 weeks of amenorrhea. Ultrasound is sometimes limited to the second trimester of pregnancy for hydranencephaly. This difficulty justifies the increasing use of antenatal magnetic resonance imaging. Antenatal diagnosis could lead to therapeutic abortion. This diagnosis was evoked on MRI on the basis of the absence of cerebral parenchyma occupied by a T2 hypersignal fluid cavity. The differential diagnosis is particularly relevant when a porencephalic cyst or alobolar holoprosencephaly is suspected[12]. Distinction between hydrocephalus and hydranencephalus is based on presence of an intact cortical envelope.

The differential diagnosis between severe congenital hydrocephalus and hydrancencephaly is difficult but important for prognosis and evaluation of treatment [12].

\section{CONCLUSION}

These observations and literature review demonstrate the value of fetal MRI for early detection of prenatal abnormalities. Ces anomalies peuvent permettre de poser l'indication d'une interruption médicale de grossesse. These abnormalities may be an indication for a medical interruption of pregnancy. In addition, our study raises the issue of fetal MRI in an algorithm for management of fetal malformations observed on ultrasound.

\section{REFERENCES}

1. Frates, M. C., Kumar, A. J., Benson, C. B., Ward, V. L., \& Tempany, C. M. (2004). Fetal anomalies: comparison of MR imaging and US for diagnosis. Radiology, 232(2), 398-404.

2. Raybaud, C., Levrier, O., Brunel, H., Girard, N., \& Farnarier, P. (2003). MR imaging of fetal brain malformations. Child's Nervous System, 19(7), 455-470.

3. Glenn, O. A., \& Barkovich, A. J. (2006). Magnetic resonance imaging of the fetal brain and spine: an increasingly important tool in prenatal diagnosis, part 1. American Journal of Neuroradiology, 27(8), 1604-1611.

4. Kubik-Huch, R. A., Huisman, T. A., Wisser, J., Gottstein-Aalame, N., Debatin, J. F., Seifert, B., ... \& Marincek, B. (2000). Ultrafast MR imaging of the fetus. American Journal of Roentgenology, 174(6), 1599-1606.

5. Stazzone, M. M., Hubbard, A. M., Bilaniuk, L. T., Harty, M. P., Meyer, J. S., Zimmerman, R. A., \& Mahboubi, S. (2000). Ultrafast MR imaging of the normal posterior fossa in fetuses. American Journal of Roentgenology, 175(3), 835-839.

6. Delorme, B., Mas-Caradec, M.C., Loisel, D. (2011). IRM foetale. In Boussion F, Biquard F, Guichet A. Le diagnostic prénatal en pratique. IssyLes-Moulineaux: Elsevier Masson SAS, 20.

7. Huppi, P. S., \& Inder, T. E. (2001, April). Magnetic resonance techniques in the evaluation of the perinatal brain: recent advances and future directions. In Seminars in neonatology (Vol. 6, No. 2, pp. 195-210). WB Saunders.

8. Adamsbaum, C., Robain, O., Cohen, P. A., Delalande, O., Fohlen, M., \& Kalifa, G. (1998). Focal cortical dysplasia and hemimegalencephaly: histological and neuroimaging correlations. Pediatric radiology, 28(8), 583-590.

9. Taylor, D. C., Falconer, M. A., Bruton, C. J., \& Corsellis, J. A. N. (1971). Focal dysplasia of the cerebral cortex in epilepsy. Journal of Neurology, Neurosurgery \& Psychiatry, 34(4), 369-387.

10. Levine, D., Barnes, P., Korf, B., \& Edelman, R. (2000). Tuberous sclerosis in the fetus: secondtrimester diagnosis of subependymal tubers with ultrafast MR imaging. American Journal of Roentgenology, 175(4), 1067-1069.

11. Adamsbaum, C., Mezzetta, L., \& Hornoy, P. (2010). Actualité sur l'imagerie par résonance magnétique (IRM) fœtale. Archives de pédiatrie, 17(12), 1749-1760.

12. Moutard, M. L., \& Fallet-Blanco, C. (2004). Pathologie neurologique malformative fœtale. EMC-Pédiatrie, 1(2), 210-231.

Cite This Article: Touré Aboulaye et al (2022). MRI Aspects of Prenatal Brain Malformations about Three Cases and Literature Review. EAS J Radiol Imaging Technol, 4(1), 1-3. 